Article

\title{
Classification of the State of Manufacturing Process under Indeterminacy
}

\author{
Muhammad Aslam * (D) and Osama Hasan Arif \\ Department of Statistics, Faculty of Science, King Abdulaziz University, Jeddah 21589, Saudi Arabia; \\ oarif@kau.edu.sa \\ * Correspondence: magmuhammad@kau.edu.sa or aslam_ravian@hotmail.com; Tel.: +966-593-329-841
}

Received: 27 August 2019; Accepted: 15 September 2019; Published: 19 September 2019

\begin{abstract}
In this paper, the diagnosis of the manufacturing process under the indeterminate environment is presented. The similarity measure index was used to find the probability of the in-control and the out-of-control of the process. The average run length (ARL) was also computed for various values of specified parameters. An example from the Juice Company is considered under the indeterminate environment. From this study, it is concluded that the proposed diagnosis scheme under the neutrosophic statistics is quite simple and effective for the current state of the manufacturing process under uncertainty. The use of the proposed method under the uncertainty environment in the Juice Company may eliminate the non-conforming items and alternatively increase the profit of the company.
\end{abstract}

Keywords: similarity index; diagnosis; process; indeterminacy; neutrosophic statistics

\section{Introduction}

To control the non-conforming products in the industry is an important task for industrial engineers. Their mission is to minimize the non-conforming product which can be achieved only if the problems in the manufacturing process can be tackled immediately. The control charts are essential tools in the industry to monitor the manufacturing process. These tools are used to indicate the state of the process. A timely indication about the state of the process leads to the high quality of the product. Epprecht et al. [1] and Chiu and Kuo [2] proposed a chart for monitoring one, and more than one, non-conforming product, respectively. Hsu [3] designed a variable chart using the improved sampling schemes. Ho and Quinino [4] proposed an attribute chart to control the variation in the process. Aslam et al. [5] and Aslam et al. [6] worked on a time-truncated chart for the Birnbaum-Saunders distribution and the Weibull distribution respectively. Jeyadurga et al. [7] worked on an attribute chart under truncated life tests.

To analyze the vague and fuzzy data, the fuzzy logic is applied. The fuzzy logic is applied to analyze the data when the experimenters are unsure about the exact values of the parameters. Therefore, the monitoring of the process having fuzzy data is done using the fuzzy-based control charts. Afshari and Gildeh [8] and Ercan Teksen and Anagun [9] worked on fuzzy attribute and variable charts, respectively. Fadaei and Pooya [10] worked on a fuzzy operating characteristic curve. For more details, the reader may refer to Jamkhaneh et al. [11] who discussed the rectifying fuzzy single sampling plan. Senturk and Erginel [12] studied variable control charts using fuzzy approach. Ercan Teksen and Anagun [9] worked on the fuzzy X-bar and R-charts. More details on fuzzy logic can be seen in Lee and Kim [13] and Grzegorzewski [14].

A fuzzy and imprecise data usually have indeterminate values. Fuzzy and vague data only considered the membership of the truth and false values. A neutrosophic logic deals with membership of truth, false and indeterminacy values. Therefore, the neutrosophic logic is useful to analyze the data 
having indeterminacy. Smarandache [15] introduced the neutrosophic statistics, which analyze the data when indeterminacy is presented. Aslam [16] and Aslam and Arif [17] introduced the neutrosophic statistics in the area of quality control. More details about the neutrosophic logic can be seen in references [18-23].

The similarity measure index (SMI) has been widely used in a variety of fields for classification purposes. In medical sciences, this index is used to classify the patients having a particular disease or not under indeterminacy, see De and Mishra [24]. By exploring the literature and to the best of the author's knowledge, there is no work on the process monitoring using SMI. In this paper, a method to classify the state of the process using SMI is introduced. The operational process of the proposed method is also given. The proposed classification method is simple in application compared to the existing method under classical statistics. It is expected that the proposed diagnosis method for the manufacturing process under the indeterminate environment will be effective, adequate and easy compared to the existing control charts under classical statistics. In Section 2, the SMI index is introduced in process control. A comparative study and application are given in Sections 3 and 4, respectively. Some concluded remarks are given in the last section.

\section{The Proposed Chart Based on SMI}

Suppose that $Z_{N}=s_{N}+u_{N} I ; Z_{N} \in\left[Z_{L}, Z_{U}\right]$ is a neutrosophic number having a determined part $s_{N}$ and an indeterminate part $u_{N} I, I \in[\operatorname{infI}, \inf U]$ denotes the indeterminacy. Note here that $Z_{N} \in\left[Z_{L}, Z_{U}\right]$ is reduced to the determined number $Z_{N}=s_{N}$ when no indeterminacy is found. The practitioners cannot record observations of the variable of interest in the precise and determined form in the presence of indeterminacy. The monitoring of the data having neutrosophic numbers using classical statistics as discussed in reference [25] may mislead decision-makers regarding the state of the process. For example, the practitioners decide the process is in the control state using classical statistics, but in fact, some observations are in the indeterminacy interval. More details on this issue can be seen in reference [26]. Suppose that $t_{U}, f_{U}$ and $I_{U}$ presents the probabilities of the non-defective, defective and indeterminate. For the classification of the state of the process, let $t=1$ and $f=0$ show that the process is in control. Therefore, the value of SMI close to 1 indicates that the process is in control and the values away from the SMI show the process is out-of-control. The SMI from De and Mishra [24] is given by:

$$
S M I=\sqrt{\left(1-\frac{\left|\left(t_{L}-t_{U}\right)-\left(I_{L}-I_{U}\right)-\left(f_{L}-f_{U}\right)\right|}{3}\right)}\left(1-\left|\left(t_{L}-t_{U}\right)+\left(I_{L}-I_{U}\right)+\left(f_{L}-f_{U}\right)\right|\right)
$$

Note here $0 \leq t_{L}, I_{L}, f_{L} \leq 1,0 \leq t_{U}, I_{U}, f_{U} \leq 1,0 \leq t_{L}+f_{L} \leq 1,0 \leq t_{U}+f_{U} \leq 1, t_{L}+I_{L}+f_{L} \leq 2$, $t_{U}+I_{U}+f_{U} \leq 2$.

Based on SMI, the following classification procedure is proposed to diagnose the state of the manufacturing process.

Step 1: Select a random sample of size $n$ and determine $t_{U}, f_{U}$ and $I_{U}$.

Step 2: Compute the values of SMI. Classify the process in-control if SMI $\geq 0.95$, otherwise, the out-of-control.

The operational process of the proposed method is also given with the help of Figure 1. 


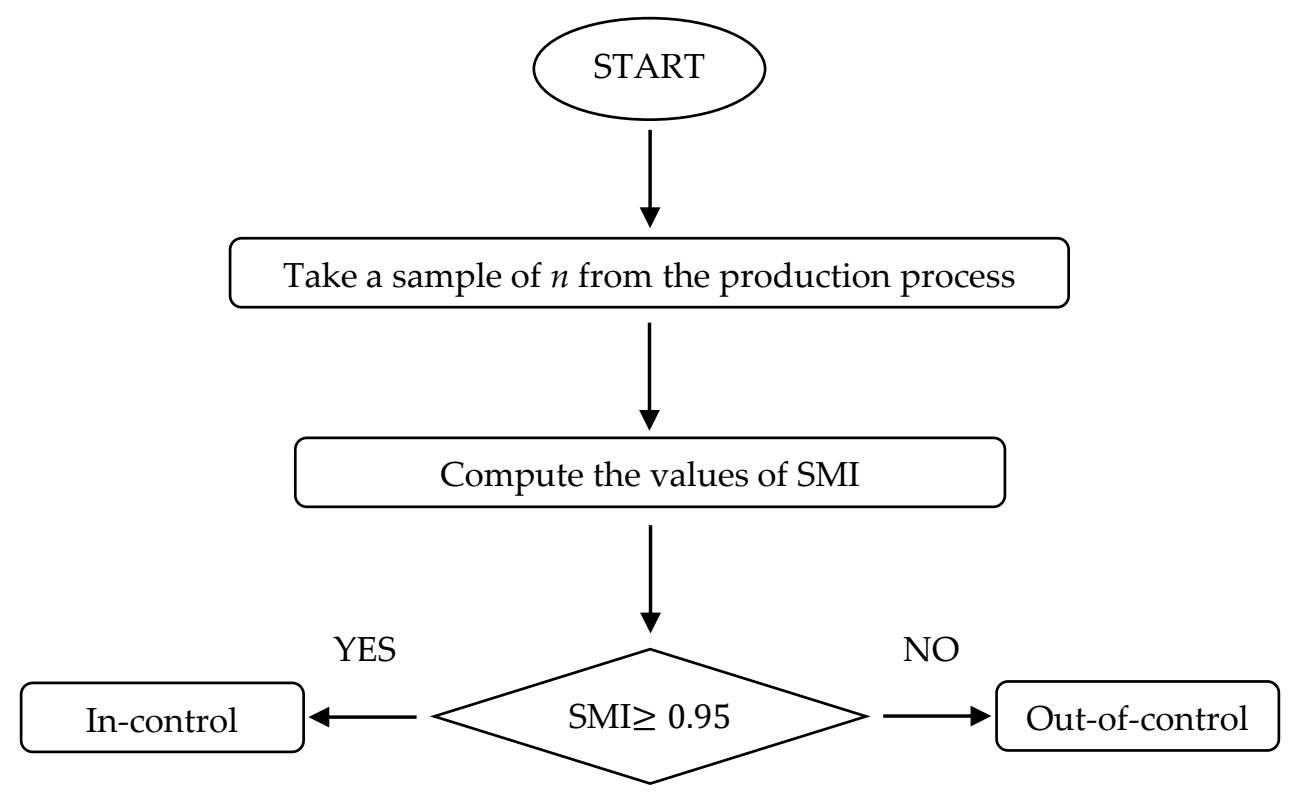

Figure 1. The operational process of the proposed method.

Note here that unlike the traditional control charts under classical statistics, the proposed chart using SMI is independent of the control limits and the control limits coefficients. The proposed chart reduces to the traditional control charts under classical statistics if no indeterminacy is found. Suppose that the probability of in-control of the process is determined from SMI. Let $S M I=P_{\text {in }}$, the $P_{\text {in }}$ for the process is given by

$$
P_{\text {in }}=\sqrt{\left(1-\frac{\left|\left(t_{L}-t_{U}\right)-\left(I_{L}-I_{U}\right)-\left(f_{L}-f_{U}\right)\right|}{3}\right)}\left(1-\left|\left(t_{L}-t_{U}\right)+\left(I_{L}-I_{U}\right)+\left(f_{L}-f_{U}\right)\right|\right)
$$

The average run length (ARL) is used to see when on the average the process is expected to be out-of-control. The ARL under indeterminacy is given by:

$$
A R L=\frac{1}{\left[\sqrt{\left(1-\frac{\left|\left(t_{L}-t_{U}\right)-\left(I_{L}-I_{U}\right)-\left(f_{L}-f_{U}\right)\right|}{3}\right)}\left(1-\left|\left(t_{L}-t_{U}\right)+\left(I_{L}-I_{U}\right)+\left(f_{L}-f_{U}\right)\right|\right)\right]}
$$

The values of $t_{U}, f_{U}$ and $I_{U}$ for various values of $n$ are given in Tables $1-3$. Tables 1 and 2 are given when $n=25$ and $n=50$, respectively. Table 3 is presented for a variable sample size. In Table 4 , the values of $P_{\text {in }}$ and ARL are given for the parameters given in Tables 1-3. The classification of the state of the process based on SMI is also presented in Table 4 . The process is said to be the in-control (IN) state if SMI $\geq 0.95$ and the out-of-control (OOC) state if SMI < 0.95. It is noted no specific trend in ARL values. The following algorithm is used to classify the state of the process using the proposed method.

Step 1: Specify $n$ and determine the values of $t_{U}, f_{U}$ and $I_{U}$.

Step 2: Use the SMI to find the probability of in-control.

Step 3: Classify the process IN if SMI $\geq 0.95$ and OOC if SMI $<0.95$. 
Table 1. Neutrosophic data when $n=25$.

\begin{tabular}{cccccccc}
\hline $\begin{array}{c}\text { Sample } \\
\text { No. }\end{array}$ & $\begin{array}{c}\text { Sample } \\
\text { Size }\end{array}$ & $\begin{array}{c}\text { Number of } \\
\text { Defective } \\
\text { Units } \boldsymbol{D}\end{array}$ & $f_{\boldsymbol{U}}$ & $\begin{array}{c}\text { Number of } \\
\text { Non-Defective } \\
\text { Units } \boldsymbol{N D}\end{array}$ & $\boldsymbol{t}_{\boldsymbol{U}}$ & $\begin{array}{c}\text { Number of } \\
\text { Indeterminate } \\
\text { Units } \boldsymbol{I}\end{array}$ & $\boldsymbol{I}_{\boldsymbol{U}}$ \\
\hline 1 & 25 & 3 & 0.12 & 21 & 0.84 & 1 & 0.04 \\
2 & 25 & 4 & 0.16 & 19 & 0.76 & 2 & 0.08 \\
3 & 25 & 2 & 0.08 & 23 & 0.92 & 0 & 0 \\
4 & 25 & 5 & 0.2 & 20 & 0.8 & 4 & 0.16 \\
5 & 25 & 2 & 0.08 & 22 & 0.88 & 1 & 0.04 \\
6 & 25 & 1 & 0.04 & 22 & 0.88 & 2 & 0.08 \\
7 & 25 & 0 & 0 & 20 & 0.8 & 5 & 0.2 \\
8 & 25 & 4 & 0.16 & 21 & 0.84 & 0 & 0 \\
9 & 25 & 6 & 0.24 & 17 & 0.68 & 2 & 0.08 \\
10 & 25 & 1 & 0.04 & 23 & 0.92 & 1 & 0.04 \\
11 & 25 & 2 & 0.08 & 20 & 0.8 & 3 & 0.12 \\
12 & 25 & 5 & 0.2 & 18 & 0.72 & 2 & 0.08 \\
13 & 25 & 4 & 0.16 & 19 & 0.76 & 2 & 0.08 \\
14 & 25 & 8 & 0.32 & 16 & 0.64 & 1 & 0.04 \\
15 & 25 & 3 & 0.12 & 21 & 0.84 & 1 & 0.04 \\
16 & 25 & 2 & 0.08 & 21 & 0.84 & 2 & 0.08 \\
17 & 25 & 5 & 0.2 & 17 & 0.68 & 3 & 0.12 \\
18 & 25 & 3 & 0.12 & 19 & 0.76 & 3 & 0.12 \\
19 & 25 & 7 & 0.28 & 17 & 0.68 & 1 & 0.04 \\
20 & 25 & 1 & 0.04 & 23 & 0.92 & 1 & 0.04 \\
21 & 25 & 0 & 0 & 23 & 0.92 & 2 & 0.08 \\
22 & 25 & 2 & 0.08 & 19 & 0.76 & 4 & 0.16 \\
23 & 25 & 5 & 0.2 & 17 & 0.68 & 3 & 0.12 \\
24 & 25 & 7 & 0.28 & 17 & 0.68 & 1 & 0.04 \\
25 & 25 & 8 & 0.32 & 17 & 0.68 & 0 & 0 \\
\hline
\end{tabular}

Table 2. Neutrosophic data when $n=50$.

\begin{tabular}{cccccccc}
\hline $\begin{array}{c}\text { Sample } \\
\text { No. }\end{array}$ & $\begin{array}{c}\text { Sample } \\
\text { Size }\end{array}$ & $\begin{array}{c}\text { Number of } \\
\text { Defective } \\
\text { Units } \boldsymbol{D}\end{array}$ & $f_{\boldsymbol{U}}$ & $\begin{array}{c}\text { Number of } \\
\text { Non-Defective } \\
\text { Units } \mathbf{N D}\end{array}$ & $\boldsymbol{t}_{\boldsymbol{U}}$ & $\begin{array}{c}\text { Number of } \\
\text { Indeterminate } \\
\text { Units } \boldsymbol{I}\end{array}$ & $\boldsymbol{I}_{\boldsymbol{U}}$ \\
\hline 1 & 50 & 1 & 0.02 & 48 & 0.96 & 1 & 0.02 \\
2 & 50 & 2 & 0.04 & 47 & 0.94 & 1 & 0.02 \\
3 & 50 & 3 & 0.06 & 45 & 0.9 & 2 & 0.04 \\
4 & 50 & 5 & 0.1 & 43 & 0.86 & 2 & 0.04 \\
5 & 50 & 2 & 0.04 & 43 & 0.86 & 5 & 0.1 \\
6 & 50 & 6 & 0.12 & 41 & 0.82 & 3 & 0.06 \\
7 & 50 & 1 & 0.02 & 46 & 0.92 & 3 & 0.06 \\
8 & 50 & 2 & 0.04 & 44 & 0.88 & 4 & 0.08 \\
9 & 50 & 7 & 0.14 & 37 & 0.74 & 6 & 0.12 \\
10 & 50 & 8 & 0.16 & 34 & 0.68 & 6 & 0.12 \\
11 & 50 & 1 & 0.02 & 47 & 0.94 & 2 & 0.04 \\
12 & 50 & 6 & 0.12 & 43 & 0.86 & 1 & 0.02 \\
13 & 50 & 1 & 0.02 & 41 & 0.82 & 8 & 0.16 \\
14 & 50 & 3 & 0.06 & 39 & 0.78 & 8 & 0.16 \\
15 & 50 & 6 & 0.12 & 41 & 0.82 & 3 & 0.06 \\
16 & 50 & 3 & 0.06 & 45 & 0.9 & 2 & 0.04 \\
17 & 50 & 9 & 0.18 & 40 & 0.8 & 1 & 0.02 \\
18 & 50 & 2 & 0.04 & 41 & 0.82 & 7 & 0.14 \\
19 & 50 & 4 & 0.08 & 46 & 0.92 & 0 & 0 \\
20 & 50 & 6 & 0.12 & 43 & 0.86 & 1 & 0.02 \\
21 & 50 & 1 & 0.02 & 47 & 0.94 & 2 & 0.04 \\
22 & 50 & 7 & 0.14 & 43 & 0.86 & 0 & 0 \\
23 & 50 & 2 & 0.04 & 45 & 0.9 & 3 & 0.06 \\
24 & 50 & 0 & 0 & 48 & 0.96 & 2 & 0.04 \\
25 & 50 & 1 & 0.02 & 48 & 0.96 & 1 & 0.02 \\
\hline
\end{tabular}


Table 3. Neutrosophic data with variable sample size.

\begin{tabular}{cccccccc}
\hline $\begin{array}{c}\text { Sample } \\
\text { No. }\end{array}$ & $\begin{array}{c}\text { Sample } \\
\text { Size }\end{array}$ & $\begin{array}{c}\text { Number of } \\
\text { Defective } \\
\text { units } \boldsymbol{D}\end{array}$ & $f_{\boldsymbol{U}}$ & $\begin{array}{c}\text { Number of } \\
\text { Non-Defective } \\
\text { Units } \boldsymbol{N D}\end{array}$ & $\boldsymbol{t}_{\boldsymbol{U}}$ & $\begin{array}{c}\text { Number of } \\
\text { Indeterminate } \\
\text { Units } \boldsymbol{I}\end{array}$ & $\boldsymbol{I}_{\boldsymbol{U}}$ \\
\hline 1 & 100 & 12 & 0.120 & 78 & 0.780 & 10 & 0.10 \\
2 & 80 & 8 & 0.100 & 67 & 0.838 & 5 & 0.06 \\
3 & 80 & 6 & 0.075 & 69 & 0.863 & 5 & 0.06 \\
4 & 100 & 9 & 0.090 & 89 & 0.890 & 2 & 0.02 \\
5 & 110 & 10 & 0.091 & 99 & 0.900 & 1 & 0.01 \\
6 & 110 & 12 & 0.109 & 98 & 0.891 & 0 & 0.00 \\
7 & 100 & 11 & 0.110 & 85 & 0.850 & 4 & 0.04 \\
8 & 100 & 16 & 0.160 & 79 & 0.790 & 5 & 0.05 \\
9 & 90 & 10 & 0.111 & 66 & 0.733 & 14 & 0.16 \\
10 & 90 & 6 & 0.067 & 72 & 0.800 & 12 & 0.13 \\
11 & 110 & 20 & 0.182 & 89 & 0.809 & 1 & 0.01 \\
12 & 120 & 15 & 0.125 & 99 & 0.825 & 6 & 0.05 \\
13 & 120 & 9 & 0.075 & 108 & 0.900 & 3 & 0.03 \\
14 & 120 & 8 & 0.067 & 107 & 0.892 & 5 & 0.04 \\
15 & 110 & 6 & 0.055 & 95 & 0.864 & 9 & 0.08 \\
16 & 80 & 8 & 0.100 & 72 & 0.900 & 0 & 0.00 \\
17 & 80 & 10 & 0.125 & 69 & 0.863 & 1 & 0.01 \\
18 & 80 & 7 & 0.088 & 68 & 0.850 & 5 & 0.06 \\
19 & 90 & 5 & 0.056 & 78 & 0.867 & 7 & 0.08 \\
20 & 100 & 8 & 0.080 & 88 & 0.880 & 4 & 0.04 \\
21 & 100 & 5 & 0.050 & 88 & 0.880 & 7 & 0.07 \\
22 & 100 & 8 & 0.080 & 91 & 0.910 & 1 & 0.01 \\
23 & 100 & 10 & 0.100 & 88 & 0.880 & 2 & 0.02 \\
24 & 90 & 6 & 0.067 & 80 & 0.889 & 4 & 0.04 \\
25 & 90 & 9 & 0.100 & 80 & 0.889 & 1 & 0.01 \\
\hline
\end{tabular}

Table 4. Classification of the process.

\begin{tabular}{ccccccccc}
\hline & $\boldsymbol{n}=\mathbf{2 5}$ & & \multicolumn{3}{c}{$\boldsymbol{n = 5 0}$} & \multicolumn{3}{c}{ Variable Sample Size } \\
\hline $\boldsymbol{P}_{\boldsymbol{i n}}$ & Classification & ARL & $\boldsymbol{P}_{\boldsymbol{i n}}$ & Classification & ARL & $\boldsymbol{P}_{\boldsymbol{i n}}$ & Classification & ARL \\
\hline 0.9451 & OOC & 18 & 0.9865 & IN & 74 & 0.9223 & OOC & 13 \\
0.9165 & OOC & 12 & 0.9797 & IN & 49 & 0.9438 & OOC & 18 \\
0.9729 & IN & 37 & 0.9660 & IN & 29 & 0.9526 & IN & 21 \\
0.8265 & OOC & 6 & 0.9521 & IN & 21 & 0.9626 & IN & 27 \\
0.9591 & IN & 24 & 0.9521 & IN & 21 & 0.9654 & IN & 29 \\
0.9591 & IN & 24 & 0.9380 & OOC & 16 & 0.9629 & IN & 27 \\
0.9309 & OOC & 14 & 0.9729 & IN & 37 & 0.9486 & OOC & 19 \\
0.9451 & OOC & 18 & 0.9591 & IN & 24 & 0.9273 & OOC & 14 \\
0.8869 & OOC & 9 & 0.9092 & OOC & 11 & 0.9040 & OOC & 10 \\
0.9729 & IN & 37 & 0.8763 & OOC & 8 & 0.9300 & OOC & 14 \\
0.9309 & OOC & 14 & 0.9797 & IN & 49 & 0.9335 & OOC & 15 \\
0.9018 & OOC & 10 & 0.9521 & IN & 21 & 0.9398 & OOC & 17 \\
0.9165 & OOC & 12 & 0.9380 & OOC & 16 & 0.9628 & IN & 27 \\
0.8717 & OOC & 8 & 0.9237 & OOC & 13 & 0.9630 & IN & 27 \\
0.9451 & OOC & 18 & 0.9380 & OOC & 16 & 0.9532 & IN & 21 \\
0.9451 & OOC & 18 & 0.9660 & IN & 29 & 0.9660 & IN & 29 \\
0.8869 & OOC & 9 & 0.9309 & OOC & 14 & 0.9526 & IN & 21 \\
0.9165 & OOC & 12 & 0.9380 & OOC & 16 & 0.9480 & OOC & 19 \\
0.8869 & OOC & 9 & 0.9729 & IN & 37 & 0.9526 & IN & 21 \\
0.9729 & IN & 37 & 0.9521 & IN & 21 & 0.9591 & IN & 24 \\
0.9729 & IN & 37 & 0.9797 & IN & 49 & 0.9591 & IN & 24 \\
0.9165 & OOC & 12 & 0.9521 & IN & 21 & 0.9695 & IN & 33 \\
0.8869 & OOC & 9 & 0.9660 & IN & 29 & 0.9591 & IN & 24 \\
0.8869 & OOC & 9 & 0.9865 & IN & 74 & 0.9610 & IN & 26 \\
0.8869 & OOC & 9 & 0.9865 & IN & 74 & 0.9619 & IN & 26 \\
\hline
\end{tabular}




\section{Comparative Study}

In this section, a comparison of the effectiveness of the proposed method is given over the control charts under classical statistics reported in reference [25]. According to Aslam et al. [26], a method which deals with indeterminacy is said to be more effective than the method which provides the determined values. The proposed method reduces to the traditional method under classical statistics if no indeterminacy is recorded. From reference [25], it is noted that the control chart under classical statistics does not consider the measure of indeterminacy which makes it limited to be used in an uncertainty environment. The performance of the existing control chart depends on the control limit coefficient which is determined through the complicated simulation process. On the other hand, the current method considered the measure of indeterminacy to evaluate the performance of the control chart. In addition, the proposed method is independent of the control limit coefficient. The proposed process can be applied easily to classify the state of the process. Note here that, the proposed method reduces to the method under classical statistics if no indeterminacy is found in the production data. The values of ARL from the proposed method and method under classical statistics discussed by Montgomery [25] are shown in Table 5 when $n=25$ and $D=2$. It is well-known theory that the smaller the values of ARL means more efficient the control chart process [25]. From Table 5, it can be seen that the proposed method provides the smaller values of ARL than the existing method. It means the proposed control chart has the ability to detect a shift in the process earlier than the method under classical statistics. For example, when $n=25$ and $d=2$, the value of ARL of the existing method from Table 5 is 37. On the other hand, the proposed method provides smaller values of ARL which are 24, 14,18 and 12. From this comparison, it is concluded that the process is classified as IN. The industrial engineers can expect the process to be out-of-control at the 37th sample by using the existing method and on the 12th sample for sample number 22 using the proposed method. Therefore, the proposed method is efficient in detecting shifts earlier than the existing method. From this comparison, is the authors concluded that the proposed method is more effective than the existing charts as it considered the measure of indeterminacy and indicated when the process was OCC.

Table 5. The comparison of the proposed method with existing method when $n=25$ and $D=2$.

\begin{tabular}{ccc}
\hline Sample No & ARL & Control Chart \\
\hline 3 & 37 & Under classical statistics \\
5 & 24 & Under neutrosophic statistics \\
11 & 14 & Under neutrosophic statistics \\
16 & 18 & Under neutrosophic statistics \\
22 & 12 & Under neutrosophic statistics \\
\hline
\end{tabular}

\section{Application}

In this section, a discussion of the application of the proposed method in an orange juice company is given. According to Montgomery [25], "Frozen orange juice concentrate is packed in 6-oz cardboard cans. These cans are formed on a machine by spinning them from cardboard stock and attaching a metal bottom panel". By inspection, it was found that a sample of 50 juice cans was formed. Some cans were found to be leaking and some were labeled as good. For some cans, the industrial engineer is indeterminate about whether the juice product is labeled as either conforming and non-conforming. Therefore, classical statistics cannot be applied to monitor the process in the presence of indeterminacy. The data for $n=50$ is shown in Table 2. The classification of the state of the process for the juice cans is shown in Table 4. From Table 4, it is noted that the first five subgroups show that the process is the IN control state. The 5th subgroup shows that the process is OOC and industrial engineer should take action to bring back the process in the IN state. It is noted that overall eight samples are in OOC state. From this study, it is concluded that the use of the proposed method to classify the state of the process is quite easy, effective and adequate to be applied under an uncertainty environment. 


\section{Conclusions and Remarks}

In this paper, the diagnosis of the manufacturing process under the indeterminate environment was presented. The similarity measure index was used to find the probability of the in-control and the out-of-control of the process. The average run length (ARL) was also computed for various values of specified parameters. An industrial example was given to explain the state of the process. An industrial example under the indeterminate environment was presented. From this study, it is concluded that the proposed diagnosis scheme under the neutrosophic statistics is quite simple and effective for the current state of the manufacturing process under uncertainty. The practitioners can apply the proposed method to save time and efforts in the industry. The proposed method using non-normal measures can be considered as future research.

Author Contributions: Conceived and designed the experiments, M.A.; Performed the experiments, M.A. Analyzed the data, M.A. and O.H.A.; Contributed reagents/materials/analysis tools, M.A.; Wrote the paper, M.A. and O.H.A.

Funding: This article was funded by the Deanship of Scientific Research (DSR) at King Abdulaziz University, Jeddah. The authors, therefore, acknowledge with thanks DSR technical and financial support.

Acknowledgments: The authors are deeply thankful to editor and reviewers for their valuable suggestions to improve the quality of this manuscript.

Conflicts of Interest: The authors declare no conflict of interest.

\section{References}

1. Epprecht, E.K.; Costa, A.F.; Mendes, F.C. Adaptive Control Charts for Attributes. IIE Trans. 2003, 35, 567-582. [CrossRef]

2. Chiu, J.-E.; Kuo, T.-I. Attribute Control Chart for Multivariate Poisson Distribution. Commun. Stat. Theory Methods 2007, 37, 146-158. [CrossRef]

3. Hsu, L.-F. Note on 'Design of double-and triple-sampling X-bar control charts using genetic algorithms'. Int. J. Prod. Res. 2004, 42, 1043-1047. [CrossRef]

4. Ho, L.L.; Quinino, R.C. An attribute control chart for monitoring the variability of a process. Int. J. Prod. Econ. 2013, 145, 263-267.

5. Aslam, M.; Arif, O.H.; Jun, C.-H. An Attribute Control Chart Based on the Birnbaum-Saunders Distribution Using Repetitive Sampling. IEEE Access 2016, 4, 9350-9360. [CrossRef]

6. Aslam, M.; Arif, O.H.; Jun, C.-H. An attribute control chart for a Weibull distribution under accelerated hybrid censoring. PLoS ONE 2017, 12, e0173406. [CrossRef] [PubMed]

7. Jeyadurga, P.; Balamurali, S.; Aslam, M. Design of an attribute np control chart for process monitoring based on repetitive group sampling under truncated life tests. Commun. Stat. Theory Methods 2018, 47, 5934-5955. [CrossRef]

8. Afshari, R.; Gildeh, B.S. Construction of fuzzy multiple deferred state sampling plan. In Proceedings of the 2017 Joint 17th World Congress of International Fuzzy Systems Association and 9th International Conference on Soft Computing and Intelligent Systems (IFSA-SCIS), Otsu, Japan, 27-30 June 2017.

9. Ercan Teksen, H.; Anagun, A.S. Different methods to fuzzy $\mathrm{X}^{-}-\mathrm{R}$ control charts used in production: Interval type-2 fuzzy set example. J. Enterp. Inf. Manag. 2018, 31, 848-866. [CrossRef]

10. Fadaei, S.; Pooya, A. Fuzzy U control chart based on fuzzy rules and evaluating its performance using fuzzy OC curve. TQM J. 2018, 30, 232-247. [CrossRef]

11. Jamkhaneh, E.B.; Sadeghpour-Gildeh, B.; Yari, G. Important criteria of rectifying inspection for single sampling plan with fuzzy parameter. Int. J. Contemp. Math. Sci. 2009, 4, 1791-1801.

12. Senturk, S.; Erginel, N. Development of fuzzy $X^{-} \sim-R \sim$ and $X^{-} \sim-S \sim$ control charts using $\alpha$-cuts. Inf. Sci. 2009, 179, 1542-1551. [CrossRef]

13. Lee, H.; Kim, S. Black-box classifier interpretation using decision tree and fuzzy logic-based classifier implementation. Int. J. Fuzzy Log. Intell. Syst. 2016, 16, 27-35. [CrossRef]

14. Grzegorzewski, P. On separability of fuzzy relations. Int. J. Fuzzy Log. Intell. Syst. 2017, 17, 137-144. [CrossRef]

15. Smarandache, F. Introduction to Neutrosophic Statistics; Infinite Study: El Segundo, CA, USA, 2014. 
16. Aslam, M. Design of Sampling Plan for Exponential Distribution under Neutrosophic Statistical Interval Method. IEEE Access 2018, 6, 64153-64158. [CrossRef]

17. Aslam, M.; Arif, O.H. Testing of Grouped Product for the Weibull Distribution Using Neutrosophic Statistics. Symmetry 2018, 10, 403. [CrossRef]

18. Broumi, S.; Bakali, A.; Talea, M.; Smarandache, F.; ALi, M. Shortest Path Problem under Bipolar Neutrosphic Setting. Appl. Mech. Mater. 2017, 859, 59-66. [CrossRef]

19. Broumi, S.; Bakali, A.; Talea, M.; Smarandache, F.; Ullah, K. Bipolar Neutrosophic Minimum Spanning Tree. Available online: https://books.google.com.sa/books?id=VopuDwAAQBAJ\&printsec $=$ frontcover\&hl=ar\#v= onepage\&q\&f=false (accessed on 25 August 2019).

20. Abdel-Basset, M.; Gunasekaran, M.; Mohamed, M.; Chilamkurti, N. Three-way decisions based on neutrosophic sets and AHP-QFD framework for supplier selection problem. Future Gener. Comput. Syst. 2018, 89, 19-30. [CrossRef]

21. Abdel-Basset, M.; Gunasekaran, M.; Mohamed, M.; Smarandache, F. A novel method for solving the fully neutrosophic linear programming problems. Neural Comput. Appl. 2018, 31, 1595-1605. [CrossRef]

22. Broumi, S.; Bakali, A.; Talea, M.; Smarandache, F.; Kishore, K.K.; Şahin, R. Shortest path problem under interval valued neutrosophic setting. J. Fundam. Appl. Sci. 2018, 10, 168-174.

23. Abdel-Basset, M.; Nabeeh, N.A.; El-Ghareeb, H.A.; Aboelfetouh, A. Utilising neutrosophic theory to solve transition difficulties of IoT-based enterprises. Enterp. Inf. Syst. 2019, 1-21. [CrossRef]

24. De, S.; Mishra, J. Inconsistent Data Using Neutrosophic Logic to Disease Diagnosis for Prevention. In Proceedings of the 13th International Conference on Recent Trends in Engineering Science and Management, School of Electronics and Communications Engineering, REVA, Bangalore, India, 23-24 April 2018.

25. Montgomery, D.C. Introduction to Statistical Quality Control; John Wiley \& Sons: Jefferson City, MO, USA, 2007.

26. Aslam, M.; Khan, N.; Khan, M.Z. Monitoring the Variability in the Process Using Neutrosophic Statistical Interval Method. Symmetry 2018, 10, 562. [CrossRef]

(C) 2019 by the authors. Licensee MDPI, Basel, Switzerland. This article is an open access article distributed under the terms and conditions of the Creative Commons Attribution (CC BY) license (http://creativecommons.org/licenses/by/4.0/). 